\title{
A COMPARATIVE STUDY OF CAUDAL BUTORPHANOL AND FENTANYL FOR ALLEVIATING POST-OPERATIVE PAIN IN INFRAUMBILICAL PROCEDURES IN CHILDREN BELOW 3 YEARS OF AGE
}

\author{
MOHAMMED IRFANULLA*, THRIVIKRAM SHENOY, RANJAN RK
}

\author{
No. 20, Ex-servicemen Colony, RT Nagar, Bangalore, Karnataka, India. Email: irfinity@gmail.com
} Received: 27 June 2018, Revised and Accepted: 19 September 2018

\section{ABSTRACT}

Objective: Caudal block is a common regional anesthetic technique used in children. However, it is limited by relatively shorter duration of analgesia. The objective of this study was to compare the analgesic efficacy of caudal blockade using butorphanol (1) and fentanyl in children below 3 years, undergoing infraumbilical surgeries.

Methods: Patients were randomly allocated to two groups of 30 each. Without premedication, patients were induced with thiopentone, relaxed with atracurium for facilitation of LMA insertion, and maintained on $\mathrm{O}_{2}, \mathrm{~N}_{2} \mathrm{O}$, and halothane. Caudal block was then performed using an aseptic technique. One group received caudal butorphanol $(25 \mu \mathrm{g} / \mathrm{kg})$ with $0.25 \%$ bupivacaine $(0.1 \mathrm{ml} / \mathrm{kg})$ and the other received fentanyl $(1 \mu \mathrm{g} / \mathrm{kg})$. Incision was allowed after 15 min of block. After the completion of surgery, LMA was removed and patients were shifted to the PACU. Non-invasive blood pressure and heart rate were recorded; pain was assessed using modified objective pain score (MOPS) $(2)$ at $2,4,6,12$, and 24 h, postoperatively. Oral paracetamol was given at a score $>4$.

Results: The mean duration of analgesia in Group F was 12.47 (standard deviation [SD] 8.216) and 19.67 (SD 7.009) in Group B (p: 0.001, HS). Mean MOPS was 4.6 in the fentanyl group as compared to 2.6 in the butorphanol group at the end of $24 \mathrm{~h}$ ( $\mathrm{p}=0.001$, HS). Thus, butorphanol provided longer duration of analgesia compared to fentanyl.

Conclusion: Caudal additives are safe in children and butorphanol provides significantly longer duration of analgesia as compared to fentanyl, thus avoiding caudal catheterization and intravenous analgesics.

Key words: Post-operative analgesia, Modified objective pain score, Caudal block, Caudal additives, Pediatric analgesia.

(C) 2019 The Authors. Published by Innovare Academic Sciences Pvt Ltd. This is an open access article under the CC BY license (http://creativecommons. org/licenses/by/4. 0/) DOI: http://dx.doi.org/10.22159/ajpcr.2019.v12i1.28180

\section{INTRODUCTION}

In the past decades, there has been a substantial progress in the understanding of infants' and children's sensation and responses to pain [1]. Pain is a challenging and poorly understood speciality as determining accurate objectives, and assessment of pain is difficult, especially in younger age group, who have long been under-medicated for acute pain. Physical pain in children was found to affect emergence from general anesthesia [2] as well as psychologically, in their adulthood.

Regional anesthetic techniques are now an integral part of perioperative and procedure-related pain management in children [3]. Caudal block is a common regional anesthetic technique, generally considered a simple and safe procedure and provides excellent analgesia during surgery as well as in the post-operative period in children. It has been found to reduce the perioperative stress response, requirement of inhalational agent, and perioperative intravenous narcotic use [4,5]. The analgesia is of superior quality with a duration of action lasting for about 4-8 h [6].

A major breakthrough in prolonging the post-operative analgesia in children was the administration of adjuvants along with local anesthetics. Initially, epinephrine with a concentration of 1:200,000 was tried for years [7]. Clonidine and ketamine as caudal adjuvants are currently used but carry the risk of bradycardia, hypotension, and post-operative delirium in children [8]. Opioids as caudal adjuvants, although debatable, are a well-known practice in children. Several drugs including morphine, fentanyl, buprenorphine, and tramadol along with anxiolytics like midazolam and alpha-agonists such as dexmedetomidine and clonidine are currently used as adjuvants along with local anesthetics for caudal block in children. Caudal butorphanol has also been studied in adults where it showed a longer lasting $(7.46 \pm 1.35 \mathrm{~h})$ analgesia with minimal side effects [9]

In the current study, we used butorphanol which is a synthetic opioid analgesic with agonist-antagonist activities at mu and kappa receptors, found to be relatively safe with fewer side effects in children. We conducted prospective, randomized, double-blind trial to compare the effects of caudal butorphanol and fentanyl with isobaric bupivacaine $(0.25 \%)$ with respect to alleviation of post-operative pain in children undergoing infraumbilical surgeries.

\section{METHODS}

After availing the approval from the Institutional Ethical Committee (Annexure 1), this study was conducted in the hospitals associated with Kasturba Medical College, Mangalore, from the year 2013 to July 2015. The study participants included 60 children aged between 6 months and 3 years undergoing infraumbilical surgeries.

\section{Design}

The study was a double-blind, prospective, randomized, clinical trial.

\section{Aim and objective}

This study aims to compare the analgesic efficacy of caudal blockade using butorphanol and fentanyl in children below 3 years undergoing infraumbilical surgeries.

\section{Inclusion criteria}

Participants of age group 6 months-3 years, of either sex, of the American Society of Anesthesiologists (ASA) physical status 1 and 2 undergoing infraumbilical surgeries were included in the study. 


\section{Exclusion criteria}

The following criteria were excluded from the study:

1. Parent/guardian refusal

2. ASA physical status 3 and 4

3. Children weighing more than $15 \mathrm{~kg}$ and $<5 \mathrm{~kg}$

4. Participants with a history of allergy to any of the study drugs

5. Hemodynamically unstable patient including coagulation abnormalities

6. Acute emergencies

7. Sacral anomalies

8. Systemic diseases including seizure disorders.

\section{Sample size}

The sample size required for correctly rejecting the null hypothesis with the power of $80 \%$ and confidence interval of $95 \%$ was calculated and was determined that 60 participants were required with 30 participants in each group.

The sample size was calculated using the formula [10]

$$
n=\frac{2\left(Z_{\alpha}+Z_{\beta}\right)^{2} \times \sigma^{2}}{d^{2}}
$$

Where,

$\mathrm{Z}_{\alpha}=95 \%$ confidence interval

$\mathrm{Z}_{\beta}=80 \%$ power

$\sigma=$ Standard deviation

$d=$ mean difference

\section{Method}

The selected patients were randomly allocated using computergenerated list of random numbers into two groups of 30 each. Ethics committee approval was obtained from Manipal University and an informed written parental consent was obtained. Pre-operative evaluation was done to all the patients. No premedication was given to any patient in either group. All patients were prior cannulated for the administration of antibiotics or drawing samples for blood investigations before shifting to the operating theater. In the operation theater, the nil-per-oral status was confirmed; standard ASA monitors were connected, intravenous line patency reconfirmed and maintenance fluid: Lactated Ringer's solution was started. Patients were induced with regular doses of thiopentone sodium (5-7 mg/kg) and neuromuscular blockade achieved with atracurium $(0.5 \mathrm{mg} / \mathrm{kg})$ to facilitate LMA insertion and were maintained on oxygen with $\mathrm{FiO}_{2}$ of 0.5 and nitrous oxide, with halothane as inhalational agent. No intravenous or per rectal analgesic drugs of any genre were administered to any patient intraoperatively. All patients in both the groups were connected to the anesthesia ventilators on volume-controlled ventilation mode using appropriate tidal volume and respiratory rate corresponding to weight.

In the two groups, Group B received caudal butorphanol at a dose of $25 \mu \mathrm{g} / \mathrm{kg}$ with $0.25 \%$ isobaric bupivacaine and Group F received fentanyl at a dose of $1 \mu \mathrm{g} / \mathrm{kg}$ with $0.25 \%$ isobaric bupivacaine. The dose of bupivacaine was calculated at $1 \mathrm{ml} / \mathrm{kg}$ without adding vasoconstrictors and keeping the toxic dose into consideration. Hemodynamic parameters such as heart rate, non-invasive blood pressure (NIBP), and end-tidal carbon dioxide were monitored in all patients.

After the induction of anesthesia, patients were placed in the lateral position. Caudal block was performed using an aseptic technique eliciting a pop with a 22 SWG needle. Immediately after the caudal block, the patients were turned supine for the performance of surgical procedure. Skin incision was allowed after 15 min of caudal block and blood pressure with heart rate was recorded just before and after surgical incision and then every 10 min till the end of surgery. If any patient responded to the incision with an increase in blood pressure $(>20 \mathrm{mmHg})$ or heart rate $(>20$ beats $/ \mathrm{min})$, it was considered as failure of caudal block. These patients were excluded from the study and rescue intraoperative analgesia with opioids was provided to them. Toward the end of surgery, injection ondansetron $0.15 \mathrm{mg} / \mathrm{kg}$ was given to all patients. After completion of surgery, neuromuscular blockade was reversed with appropriate doses of neostigmine and atropine. LMA was removed when the patient was awake and sent to recovery room and then to the post-operative ward for observation.

In the recovery room and post-operative ward, when the child was awake, the investigator, unaware of the method of analgesia chosen, recorded the NIBP and heart rate, and assessed the pain at 2, 4, 6, 12 , and $24 \mathrm{~h}$, postoperatively. Post-operative pain was assessed using "modified objective pain score (MOPS)" [11]. Rescue analgesia in the form of oral paracetamol $(20 \mathrm{mg} / \mathrm{kg})$ was given at a score $>4$. Side effects/complications were also noted and recorded (Table A).

\section{OBSERVATIONS AND RESULTS}

Demographic data of both the groups were compared. Table 1 shows that there was no significant statistically difference. Thus, the two groups were comparable in terms of age and weight (Tables $1 \mathrm{a}$ and b, 2 and Graphs 1-4).

The mean duration of analgesia in Group $\mathrm{F}$ was 12.47 with a standard deviation of 8.216, and in Group B, mean was 19.67 with a standard deviation of 7.009. The longest duration of action in Group F was $12 \mathrm{~h}$ (MOPS 2) and the shortest duration was $2 \mathrm{~h}$ (MOPS 5) in Group F. In contrast, the longest duration of action was $24 \mathrm{~h}$ (MOPS 0 ) and the shortest was 6 h (MOPS 6) in Group B (Tables 3-6).

The minimum MOPS in the first $2 \mathrm{~h}$ remained 0 in both the groups but reached a maximum of 5 in fentanyl Group (F) and 3 in the butorphanol group (B). In the next $2 \mathrm{~h}$, minimum MOPS remained at 0 in both the groups but reached a maximum of 4 in fentanyl Group (F) and 3 in the butorphanol Group (B). At 6 h, minimum MOPS was 1 in fentanyl (F) group and 0 in the butorphanol (B) group and a maximum of 6 in the fentanyl (F) group and 4 in the butorphanol (B) group. At $12 \mathrm{~h}$, the MOPS

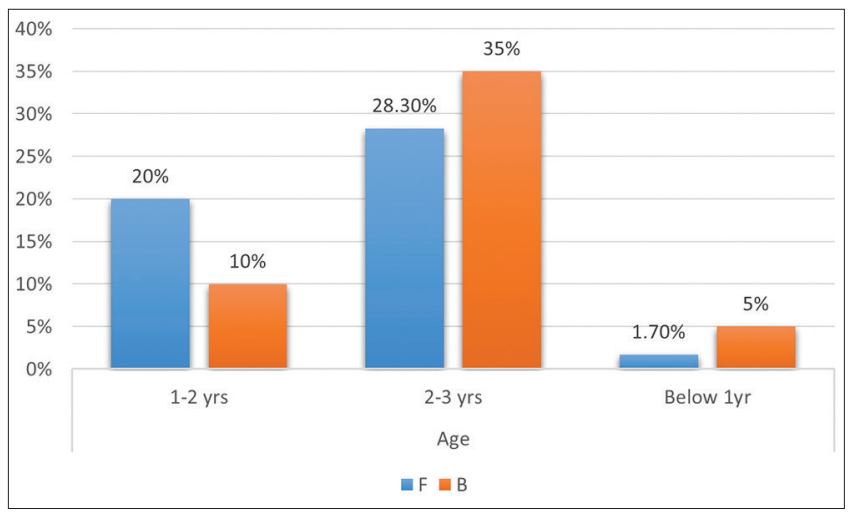

Graph 1: Age distribution

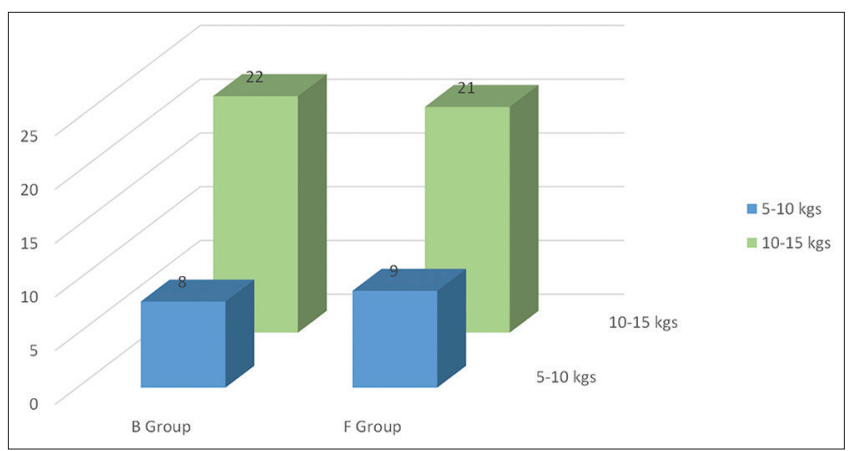

Graph 2: Weight distribution 
Table a: Pain score

\begin{tabular}{llll}
\hline MOPS & & & \\
\hline Score & $\mathbf{0}$ & $\mathbf{1}$ & $\mathbf{2}$ \\
\hline Movement & None & Restless & Thrashing \\
Agitation & Asleep/calm & Mild & Hysterical \\
Posture & Normal & Flexed & Holds injury site \\
Verbal & Asleep/no complaint & Complains but cannot localize & Complains and localizes \\
\hline
\end{tabular}

Table 1a: Age distribution

\begin{tabular}{llll}
\hline Age & Group & Total \\
\cline { 2 - 3 } & F & B & \\
\hline 1-2 years & $12(20)$ & $6(10.0)$ & $18(30.0)$ \\
2-3 years & $17(28.3)$ & $21(35.0)$ & $38(63.3)$ \\
Below 1 year & $1(1.7)$ & $3(5.0)$ & $4(6.7)$ \\
Total & $30(50.0)$ & $30(50.0)$ & $60(100.0)$ \\
\hline
\end{tabular}

$\chi^{2}$ test; $\mathrm{p}=0.181$, NS

Table 1b: Weight distribution (kg)

\begin{tabular}{lllll}
\hline Group & $\mathbf{N}$ & Mean & SD & t-test p value \\
\hline F & 30 & 12.80 & 2.932 & 0.749 \\
B & 30 & 13.07 & 3.473 & NS \\
\hline SD Standard deviation & &
\end{tabular}

Table 2: Duration of analgesia (hours)

\begin{tabular}{lllll}
\hline Group & $\mathbf{N}$ & Mean & SD & Mann-Whitney U-test p value \\
\hline F & 30 & 12.47 & 8.216 & 0.001 \\
B & 30 & 19.67 & 7.009 & HS \\
\hline
\end{tabular}

SD: Standard deviation

Table 3: Intraoperative hemodynamic monitoring

\begin{tabular}{|c|c|c|c|c|c|}
\hline \multicolumn{6}{|c|}{ Heart rate (per minute) } \\
\hline Interval & Group & $\mathbf{N}$ & Mean & SD & p value \\
\hline \multirow[t]{2}{*}{ Pre-induction } & $\mathrm{F}$ & 30 & 107.70 & 16. 382 & 0.897 \\
\hline & B & 30 & 107.17 & 15. 407 & \\
\hline \multirow[t]{2}{*}{ Post-induction } & $\mathrm{F}$ & 30 & 107.33 & 15.632 & 0.390 \\
\hline & B & 30 & 110.47 & 12.162 & \\
\hline \multirow[t]{2}{*}{$10 \mathrm{~min}$} & $\mathrm{~F}$ & 30 & 109.50 & 11.013 & 0.872 \\
\hline & B & 30 & 109.97 & 11.343 & \\
\hline \multirow[t]{2}{*}{$20 \mathrm{~min}$} & $\mathrm{~F}$ & 30 & 107.57 & 11.892 & 0.833 \\
\hline & B & 30 & 106.93 & 11. 228 & \\
\hline \multirow[t]{2}{*}{$30 \mathrm{~min}$} & $\mathrm{~F}$ & 30 & 104.00 & 10.780 & 0.922 \\
\hline & B & 30 & 103.73 & 10. 275 & \\
\hline \multirow[t]{2}{*}{$40 \mathrm{~min}$} & $\mathrm{~F}$ & 30 & 103.00 & 10.168 & 0.909 \\
\hline & B & 30 & 102.70 & 9.994 & \\
\hline \multirow[t]{2}{*}{$50 \mathrm{~min}$} & $\mathrm{~F}$ & 30 & 102.13 & 9.829 & 0.857 \\
\hline & B & 30 & 101.67 & 10.090 & \\
\hline \multirow[t]{2}{*}{$60 \mathrm{~min}$} & $\mathrm{~F}$ & 30 & 101.97 & 10.284 & 0.774 \\
\hline & B & 30 & 101.20 & 10.274 & \\
\hline \multirow[t]{2}{*}{$70 \mathrm{~min}$} & $\mathrm{~F}$ & 13 & 94.93 & 9.294 & 0.087 \\
\hline & B & 18 & 100.63 & 9.069 & \\
\hline \multirow[t]{2}{*}{$80 \mathrm{~min}$} & $\mathrm{~F}$ & 8 & 96.11 & 10.410 & 0.777 \\
\hline & B & 11 & 97.36 & 9.113 & \\
\hline \multirow[t]{2}{*}{$90 \mathrm{~min}$} & $\mathrm{~F}$ & 5 & 98.00 & 10.368 & 0.798 \\
\hline & B & 7 & 96.86 & 4.488 & \\
\hline \multirow[t]{2}{*}{$100 \mathrm{~min}$} & $\mathrm{~F}$ & 1 & 85.00 & N/A & \\
\hline & B & 1 & 100.00 & N/A & \\
\hline
\end{tabular}

SD: Standard deviation

score remained at minimum of 1 and a maximum of 5 in the fentanyl (F) group and a minimum of 0 and a maximum of 5 in the butorphanol (B) group. Finally, at $24 \mathrm{~h}$, the minimum score remained at a minimum of 5

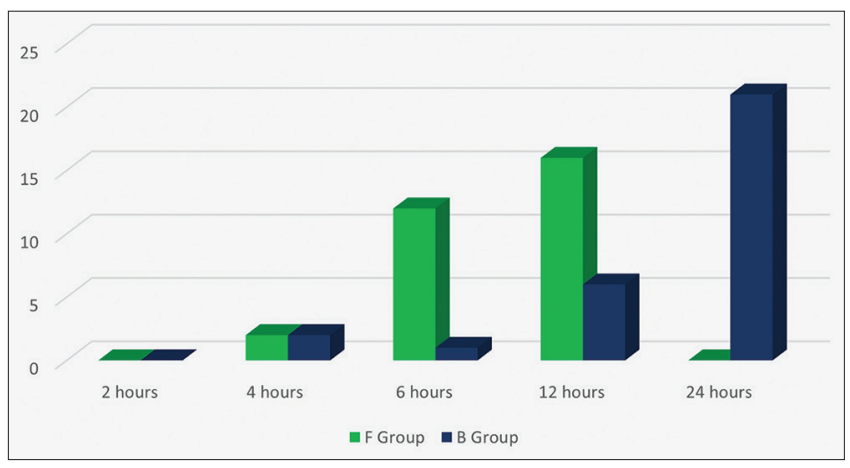

Graph 3: Duration of analgesia

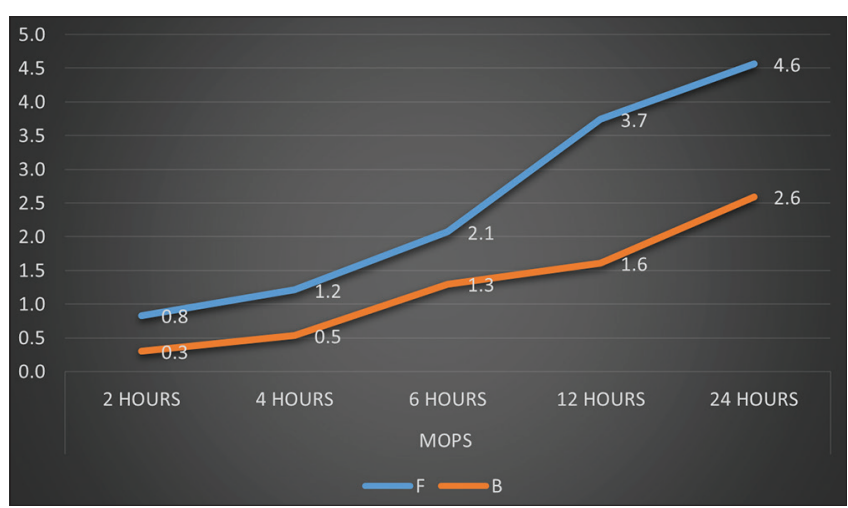

Graph 4: The duration of analgesia, particularly in the B group, was considerably longer when compared to those done by Vinitha et al., in 2006

and a maximum of 6 in the fentanyl (F) group, and at the same time, the minimum score still remained minimum at 0 and maximum of 5 in the butorphanol group.

The above observation shows that the mean MOPS was significantly lesser in the B group for each time measured with $\mathrm{p}<0.05$ at all intervals.

All the patients in both the groups received rescue analgesia when their individual score reached more than 4 .

\section{Statistical analysis}

Statistical analysis was done with Student's paired $t$-test and $\chi^{2}$ test. A statistical package SSPS version 15.0 was used to do the analysis. $\mathrm{p}<0.05$ was considered statistically significant.

\section{DISCUSSION}

Caudal epidural anesthesia has long gained popularity as a safe regional technique for surgeries in pediatric age group. Commonly a single shot caudal is performed known as "Kiddie caudal" along with general anesthesia for intra- and post-operative analgesia with high success rates [12]. The main disadvantage with single shot technique is the limited duration of analgesia provided with bupivacaine $(6.8 \pm 2.9$ h) [10]. Many drugs have been subsequently experimented in search of the one which prolongs the analgesia with minimal side 
Table 4: Systolic blood pressure (mmHg)

\begin{tabular}{|c|c|c|c|c|c|}
\hline Interval & Group & $\mathbf{N}$ & Mean & SD & p value \\
\hline \multirow[t]{2}{*}{ Pre-induction } & $\mathrm{F}$ & 30 & 97.00 & 8.670 & 0.097 \\
\hline & B & 30 & 93.83 & 5.522 & \\
\hline \multirow[t]{2}{*}{ Post-induction } & $\mathrm{F}$ & 30 & 93.17 & 8.558 & 0.105 \\
\hline & B & 30 & 89.93 & 6.496 & \\
\hline \multirow[t]{2}{*}{$10 \mathrm{~min}$} & $\mathrm{~F}$ & 30 & 92.63 & 5.611 & 0.884 \\
\hline & B & 30 & 92.40 & 6.673 & \\
\hline \multirow[t]{2}{*}{$20 \mathrm{~min}$} & $\mathrm{~F}$ & 30 & 94.17 & 6.958 & 0.535 \\
\hline & B & 30 & 93.17 & 5.331 & \\
\hline \multirow[t]{2}{*}{$30 \mathrm{~min}$} & $\mathrm{~F}$ & 30 & 94.00 & 6.074 & 0.060 \\
\hline & B & 30 & 91.23 & 5.063 & \\
\hline \multirow[t]{2}{*}{$40 \mathrm{~min}$} & $\mathrm{~F}$ & 30 & 92.83 & 5.676 & 0.089 \\
\hline & $\mathrm{B}$ & 30 & 90.53 & 4.577 & \\
\hline \multirow[t]{2}{*}{$50 \mathrm{~min}$} & $\mathrm{~F}$ & 30 & 94.00 & 6.486 & 0.181 \\
\hline & $\mathrm{B}$ & 30 & 92.00 & 4.842 & \\
\hline \multirow[t]{2}{*}{$60 \mathrm{~min}$} & $\mathrm{~F}$ & 30 & 94.00 & 6.486 & 0.094 \\
\hline & $\mathrm{B}$ & 30 & 91.50 & 4.762 & \\
\hline \multirow[t]{2}{*}{$70 \mathrm{~min}$} & $\mathrm{~F}$ & 13 & 92.31 & 4.837 & 0.728 \\
\hline & B & 18 & 91.67 & 5.145 & \\
\hline \multirow[t]{2}{*}{$80 \mathrm{~min}$} & $\mathrm{~F}$ & 8 & 93.75 & 5.175 & 0.658 \\
\hline & B & 11 & 92.73 & 4.671 & \\
\hline \multirow[t]{2}{*}{$90 \mathrm{~min}$} & $\mathrm{~F}$ & 5 & 94.00 & 5.477 & 0.356 \\
\hline & B & 7 & 91.43 & 3.780 & \\
\hline \multirow[t]{2}{*}{$100 \mathrm{~min}$} & $\mathrm{~F}$ & 1 & 100.00 & $\mathrm{~N} / \mathrm{A}$ & $\mathrm{N} / \mathrm{A}$ \\
\hline & B & 1 & 90.00 & $\mathrm{~N} / \mathrm{A}$ & \\
\hline
\end{tabular}

SD: Standard deviation

Table 5: Diastolic blood pressure (mmHg)

\begin{tabular}{|c|c|c|c|c|c|}
\hline Interval & Group & $\mathbf{N}$ & Mean & SD & p value \\
\hline \multirow[t]{2}{*}{ Pre-induction } & $\mathrm{F}$ & 30 & 60.00 & 6.017 & 0.299 \\
\hline & B & 30 & 58.60 & 4.174 & \\
\hline \multirow[t]{2}{*}{ Post-induction } & $\mathrm{F}$ & 30 & 57.33 & 9.072 & 0.124 \\
\hline & B & 30 & 53.83 & 8.272 & \\
\hline \multirow[t]{2}{*}{$10 \mathrm{~min}$} & $\mathrm{~F}$ & 30 & 58.60 & 7.668 & 0.729 \\
\hline & B & 30 & 58.00 & 5.509 & \\
\hline \multirow[t]{2}{*}{$20 \mathrm{~min}$} & $\mathrm{~F}$ & 30 & 57.83 & 6.654 & 0.913 \\
\hline & B & 30 & 57.67 & 5.040 & \\
\hline \multirow[t]{2}{*}{$30 \mathrm{~min}$} & $\mathrm{~F}$ & 30 & 58.33 & 5.774 & 0.437 \\
\hline & B & 30 & 57.27 & 4.734 & \\
\hline \multirow[t]{2}{*}{$40 \mathrm{~min}$} & $\mathrm{~F}$ & 30 & 58.17 & 5.490 & 0.696 \\
\hline & B & 30 & 57.67 & 4.302 & \\
\hline \multirow[t]{2}{*}{$50 \mathrm{~min}$} & $\mathrm{~F}$ & 30 & 58.50 & 4.939 & 0.343 \\
\hline & B & 30 & 57.33 & 4.498 & \\
\hline \multirow[t]{2}{*}{$60 \mathrm{~min}$} & $\mathrm{~F}$ & 30 & 58.50 & 4.939 & 0.296 \\
\hline & B & 30 & 57.17 & 4.857 & \\
\hline \multirow[t]{2}{*}{$70 \mathrm{~min}$} & $\mathrm{~F}$ & 13 & 56.54 & 4.737 & 0.690 \\
\hline & B & 18 & 57.22 & 4.609 & \\
\hline \multirow[t]{2}{*}{$80 \mathrm{~min}$} & $\mathrm{~F}$ & 8 & 56.25 & 5.175 & 0.373 \\
\hline & B & 11 & 58.18 & 4.045 & \\
\hline \multirow[t]{2}{*}{$90 \mathrm{~min}$} & $\mathrm{~F}$ & 5 & 58.00 & 4.472 & 0.454 \\
\hline & B & 7 & 55.71 & 5.345 & \\
\hline \multirow[t]{2}{*}{$100 \mathrm{~min}$} & $\mathrm{~F}$ & 1 & 50.00 & N/A & $\mathrm{N} / \mathrm{A}$ \\
\hline & B & 1 & 60.00 & $\mathrm{~N} / \mathrm{A}$ & \\
\hline
\end{tabular}

SD: Standard deviation effects including opioids, $\alpha$ agonists, and others. The current study is a simple research in finding out a better and a longer additive to the already widely practiced caudal block.

Fentanyl is a phenylpiperidine-derived synthetic opioid agonist that is structurally related to meperidine. As an analgesic, fentanyl is 75-125 times more potent than morphine and synergistically effective with local anesthetics [13]. It is highly lipid soluble and rapidly crosses the blood-brain barrier. It also has a high rate of redistribution, and hence, the level in the plasma and cerebrospinal fluid declines rapidly. It is metabolized by the liver and excreted by the kidneys. Constant et al., in 1998, noticed a statistically significant prolonged duration of analgesia in children with lower visual analog score scores in the first $4 \mathrm{~h}$ of post-operative period who received bupivacaine with fentanyl than bupivacaine alone but vomiting was the main complication [14]. They observed clonidine to be better substitute than fentanyl in terms of complications. Comparable to this study, Sharmila et al. in their comparative study of caudal fentanyl and ketamine noticed a similar duration of analgesia in the first $4 \mathrm{~h}$ with fentanyl. They also used serum insulin, cortisol, and glucose as markers for neuroendocrine stress response (NESR), which was not done in any of the previous studies. It was concluded that ketamine $0.5 \mathrm{mg} / \mathrm{kg}$ provided a longer duration of analgesia, which was statistically significant; and least NESR was with ketamine which, however, was not statistically significant [15]. Desai further concluded that the children who received $1 \mu \mathrm{g} / \mathrm{kg}$ of fentanyl experienced longer duration of analgesia than patients who received only $0.5 \mu \mathrm{g} / \mathrm{kg}$ of fentanyl [16].

Butorphanol is a morphinan congener having a nitrogen-substituted 3,14-dihydroxymorphine. This synthetic member of the benzomorphan series is structurally similar to other drugs having various degrees of narcotic agonist and antagonist properties at room temperature. Butorphanol exists as white water-soluble crystals. Compared with pentazocine, its agonist effects are about 20 times greater, whereas its antagonist actions are 10-30 times greater. It is speculated that butorphanol has a (a) low affinity for $\mu$ receptors to produce antagonism, (b) moderate affinity for $\kappa$ receptors to produce analgesia and anti-shivering effects, and (c) minimal affinity for $\sigma$ receptors, so the incidence of dysphoria is low.

Singh et al., in 2006, compared the efficacy of caudal butorphanol in three groups of patients who received $1 \mathrm{ml} / \mathrm{kg}$ of $0.25 \%$ bupivacaine alone (L group). Among the two other groups, Group B received butorphanol $25 \mu \mathrm{g} / \mathrm{kg}$ only in saline and Group LB received $0.25 \%$ bupivacaine and $25 \mu \mathrm{g} / \mathrm{kg}$ of butorphanol through caudal route. Mean duration of analgesia was significantly higher in LB group with $p=0.001$, but the incidence of nausea and vomiting was higher in butorphanol (B) alone and combined group with bupivacaine (LB) but not statistically significant [10].

Similarly, Gupta et al., in 2009, made a comparative study in three groups of $0.25 \%$ of bupivacaine alone with a combination of the same with $20 \mu \mathrm{g} / \mathrm{kg}$ of butorphanol and $1 \mathrm{mg} / \mathrm{kg}$ of tramadol. The duration of analgesia was $435.83 \mathrm{~min}$ in the group who received butorphanol

Table 6: Comparison between the groups

\begin{tabular}{|c|c|c|c|c|c|c|c|c|c|}
\hline MOPS & Group & $\mathbf{N}$ & Minimum & Maximum & Mean & SD & Median & Mann-Whitney U-test $\mathrm{Z}$ value & p value \\
\hline \multirow[t]{2}{*}{$2 \mathrm{~h}$} & $\mathrm{~F}$ & 30 & 0 & 5 & 0.83 & 1.117 & 1 & 2.74 & 0.006 \\
\hline & $\mathrm{B}$ & 30 & 0 & 3 & 0.3 & 0.702 & 0 & & HS \\
\hline \multirow[t]{2}{*}{$4 \mathrm{~h}$} & $\mathrm{~F}$ & 29 & 0 & 4 & 1.21 & 1.013 & 1 & 3.29 & 0.001 \\
\hline & $\mathrm{B}$ & 30 & 0 & 3 & 0.53 & 1.008 & 0 & & HS \\
\hline \multirow[t]{2}{*}{$6 \mathrm{~h}$} & $\mathrm{~F}$ & 29 & 1 & 6 & 2.07 & 1.132 & 2 & 3.56 & 0 \\
\hline & B & 30 & 0 & 4 & 1.3 & 1.291 & 1 & & HS \\
\hline $12 \mathrm{~h}$ & $\mathrm{~F}$ & 27 & 1 & 5 & 3.74 & 1.318 & 4 & 5.07 & 0 \\
\hline \multirow[t]{2}{*}{$24 \mathrm{~h}$} & $\mathrm{~F}$ & 16 & 5 & 6 & 4.56 & 1.094 & 5 & 3.4 & 0.001 \\
\hline & B & 27 & 0 & 5 & 2.59 & 1.623 & 2 & & HS \\
\hline
\end{tabular}

SD: Standard deviation 
(statistically significant $\mathrm{p}$ value, 0.01 ), $302.25 \mathrm{~min}$ in bupivacaine alone, and surprisingly, $291.08 \mathrm{~min}$ in the group who received tramadol with a high incidence of vomiting [17].

In the present prospective randomized double-blind study, we compared the efficacy of caudal fentanyl in a dose of $1 \mu \mathrm{g} / \mathrm{kg}$ and butorphanol $25 \mu \mathrm{g} / \mathrm{kg}$ with $0.25 \%$ bupivacaine in 60 patients of two groups $\mathrm{F}$ and B, respectively, of 30 each. The sample population were comparable in terms of demographics; age and weight which were statistically insignificant. At induction, intraoperatively and postoperatively, we noticed a stable hemodynamic status in terms of heart rate and systolic and diastolic blood pressure which was not statistically significant $(\mathrm{p}>0.01)$.

When comparing the two groups, the MOPS remained at 0 as minimum in the first $4 \mathrm{~h}$ in both the groups but remained higher at 5 which required rescue analgesia in the fentanyl group making it statistically significant. No patients in B group required analgesics in any form in the first $4 \mathrm{~h}$. At the end of $6 \mathrm{~h}$, the minimum scores remained at 0 and 1 in butorphanol (B) and fentanyl (F) groups, but the maximum scores still remained at 4 in B group and 6 in the fentanyl group requiring rescue analgesia. At $12 \mathrm{~h}$, the MOPS remained at a minimum of 1 and a maximum of 5 in the fentanyl (F) group and a minimum of 0 and a maximum of 5 in the butorphanol (B) group. Finally, at $24 \mathrm{~h}$, the minimum score remained at 5 and a maximum of 6 in the fentanyl group, and at the same time, the minimum score still remained at 0 and maximum of 5 in butorphanol group.

The mean duration of analgesia was significantly higher in Group B (19.67 h, standard deviation [SD]: 7.009) as compared to Group F (12.47 h, SD 8.216) ( $p=0.001$, highly significant). Minimum MOPS recorded at each hour $(2,4,6,12$, and $24 \mathrm{~h})$ was $<2$ for entire $24 \mathrm{~h}$ period for both the groups; however, the MOPS recorded at each hour for Group B had significantly lower maximum pain score 3 at $2^{\text {nd }} \mathrm{h}$ as compared to Group F 5 with p=0.006 (highly significant), 5 and 6 at $6^{\text {th }} \mathrm{h}$, respectively, with p value of 0 (highly significant), and 6 and 5 at $24^{\text {th }} \mathrm{h}$, respectively, with $\mathrm{p}=0.001$ (highly significant). Mean MOPS was $<5$ for entire $24 \mathrm{~h}$ period for both the groups; however, mean MOPS was significantly lesser in Group B at each recorded hour with $\mathrm{p}<0.05$.

\section{Complications}

No complications were noticed in terms of failure of analgesia, postoperative hypoventilation, nausea and vomiting, retention of urine requiring catheterization, itching, or dysphoric reactions in any of the patients in both the groups.

However, there was no long-term follow-up with the patients; hence, long-term side effects cannot be ruled out, which is one of the limitations of this study.

\section{CONCLUSION}

1. Adjuvants such as fentanyl $1 \mu \mathrm{g} / \mathrm{kg}$ and butorphanol $25 \mu \mathrm{g} / \mathrm{kg}$ with bupivacaine $0.25 \%$ for intra- and post-operative analgesia are safe in children.

2. Reduce the requirement of potent inhalational agents and the need for subsequent analgesics in the post-operative period.

3. Stable hemodynamic status with both fentanyl and butorphanol.

4. Butorphanol offers advantages of the longer duration of analgesia than fentanyl.

5. Avoid caudal catheterization and subsequent catheter-related complications.

6. No complications such as nausea and vomiting. Although postoperative vomiting is a known complication with butorphanol, the incidence is masked due to intraoperative ondansetron.
7. No delayed respiratory depression, itching, dysphoric reaction, and retention of urine. Post-operative motor blockade is not a concern with parents in any of the patients.

8. No neurological sequelae.

9. Decreased parental anxiety and increased satisfaction.

10. Reduced cost factor.

\section{AUTHORS' CONTRIBUTION}

Dr. Mohammed Irfanulla: Conceived and designed the analysis, collected and contributed data, performed analysis, and wrote the paper. Dr. TV. Shenoy: Conceived and designed the analysis, performed the analysis, and contributed in writing of paper. Dr. Ranjan RK: Conceived and designed the analysis, and performed analysis.

\section{CONFLICTS OF INTEREST}

Nil.

\section{REFERENCES}

1. Anand KJ, Coskun V, Thrivikraman KV, Nemeroff CB, Plotsky PM. Long-term behavioral effects of repetitive pain in neonatal rat pups. Physiol Behav 1999;66:627-37.

2. Reduque LL, Verghese ST. Paediatric emergence delirium. Contin Educ Anaesth Crit Care Pain 2012;13:39-41.

3. Senel AC, Akyol A, Dohman D, Solak M. Caudal bupivacaine tramadol combination for postoperative analgesia in pediatric herniorrhaphy. Acta Anesthesiol Scand 2001;45:786-9.

4. Khahil SN, Hanna F, Farag A, Govindaraj R, Vije H, Kee S, et al. Presurgical caudal block attenuates stress response in children. Middle East J Anaesthesiol 2005;18:391-400

5. Eti Z, Batirel H, Göüs FY. A retrospective survey of caudal analgesia in 1981 paediatric patients. Br J Anaesth 1999;82:100.

6. Cook B, Grubb DJ, Aldridge LA, Doyle E. Comparison of the effects of adrenaline, clonidine and ketamine on the duration of caudal analgesia produced by bupivacaine in children. Br J Anaesth 1995;75:698-701.

7. De Beer DA, Thomas ML. Caudal additives in children - Solutions or problems? Br J Anaesth 2003:90:487-98.

8. Kumar P, Rudra A, Pan AK, Acharya A. Caudal additives in pediatrics: A comparison among midazolam, ketamine, and neostigmine coadministered with bupivacaine. Anesth Analg 2005;101:69-73.

9. Venkatraman R, Sandhiya R. Evaluation of efficacy of epidural butorphanol tartrate for postoperative analgesia. Int J Pharm Pharm Sci 2014:7:52-4.

10. Singh V, Kanaujia A, Singh GP. Efficacy of caudal butorphanol. Indian J Pediatr 2006;73:147-50.

11. Wilson G, Doyle E. Validation of three paediatric pain scores for use by parents. Anaesthesia 1996;51:1005-7.

12. Dalens B, Hasnaoui A. Caudal anesthesia in pediatric surgery: Success rate and adverse effects in 750 consecutive patients. Anesth Analg 1989;68:83-9.

13. Curatolo M, Petersen-Felix S, Scaramozzino P, Zbinden A. Epidural fentanyl, adrenaline and clonidine as adjuvants to local anaesthetics for surgical analgesia: Meta-analyses of analgesia and side-effects. Acta Anaesthesiol Scand 1998:42:910-20

14. Constant I, Gall O, Gouyet L, Chauvin M, Murat I. Addition of clonidine or fentanyl to local anaesthetics prolongs the duration of surgical analgesia after single shot caudal block in children. Br J Anaesth 1998;80:294-8.

15. Chaudhary S, Madhu S, Ahuja S, Yadav S, Joshi N. Efficacy of caudal fentanyl and ketamine on post-operative pain and neuroendocrine stress response in children undergoing infraumbilical and perineal surgery: A pilot study. J Anaesthesiol Clin Pharm 2015;31:104-9.

16. Desai DJ, Swadia VN, Gupta KK. Comparative study of two different doses of fentanyl with $0.25 \%$ bupivacaine through caudal route for paediatric anaesthesia and postoperative analgesia. J Anaesth Clin Pharm 2008;24:31-4

17. Gupta N, Anand S, Gulati S, Gupta SD, Kapoor BB. Comparison of tramadol and butorphanol for analgesic efficacy and safety. JK Sci 2008; 10:132-4. 
ANNEXURE 1
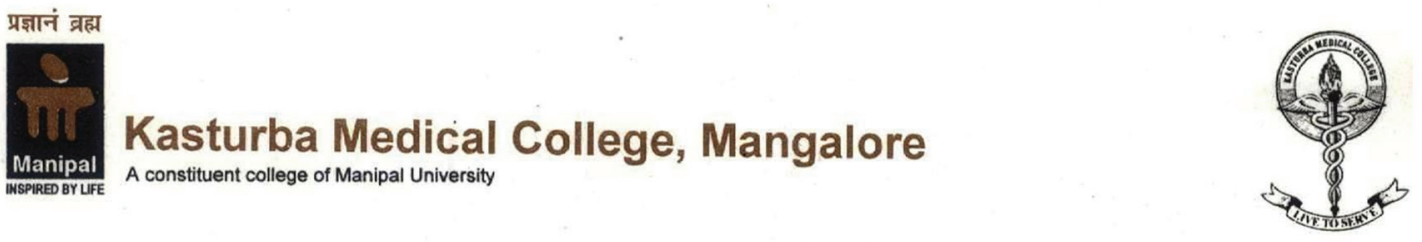

\section{Institutional Ethics Committee}

Communication of the Decision of the Institutional Ethics Committee

Wednesday $18^{\text {th }}$ December 2013

IEC KMC MLR 12-13/258

\begin{tabular}{|l|l|l|}
\hline Protocol title & $:$ & $\begin{array}{l}\text { A Comparative study of Caudal Butorphanol and Fentanyl } \\
\text { for alleviating post-operative pain in infraumbilical } \\
\text { procedures in children below three years of age }\end{array}$ \\
\hline $\begin{array}{l}\text { Principal Investigator } \\
\begin{array}{l}\text { Guide/Co-Guide/Co- } \\
\text { Investigators }\end{array}\end{array}$ & & Dr. Mohammed Irfanulla \\
\hline $\begin{array}{c}\text { Name \& Address of Institution } \\
>\text { Approved }\end{array}$ & $:$ & $\begin{array}{l}\text { Department of Anaesthesiology } \\
\text { Kasturba Medical College Mangalore }\end{array}$ \\
\hline New / review & $:$ & New \\
\hline Date of review (DD/M/YYY & & $18 / 12 / 2013$ \\
\hline $\begin{array}{c}\text { Decision of the IEC } \\
>\text { Rejected }\end{array}$ & $:$ & Approved from $18 / 12 / 2013$ \\
\hline Remarks & $:$ & Approved for the study period as mentioned in protocol \\
\hline
\end{tabular}

Please Note*

- Inform IEC immediately in case any Adverse events and Serious adverse event

- Inform IEC in case of any amendments to the protocol, change of study procedure, site and Investigator and premature termination of study with reasons along with summary.

- Final \& Yearly Reports to be submitted to IEC.

- Members of IEC have right to monitor the study with prior intimation.

- A copy of the consent document to be given to the study participant giving the consent.
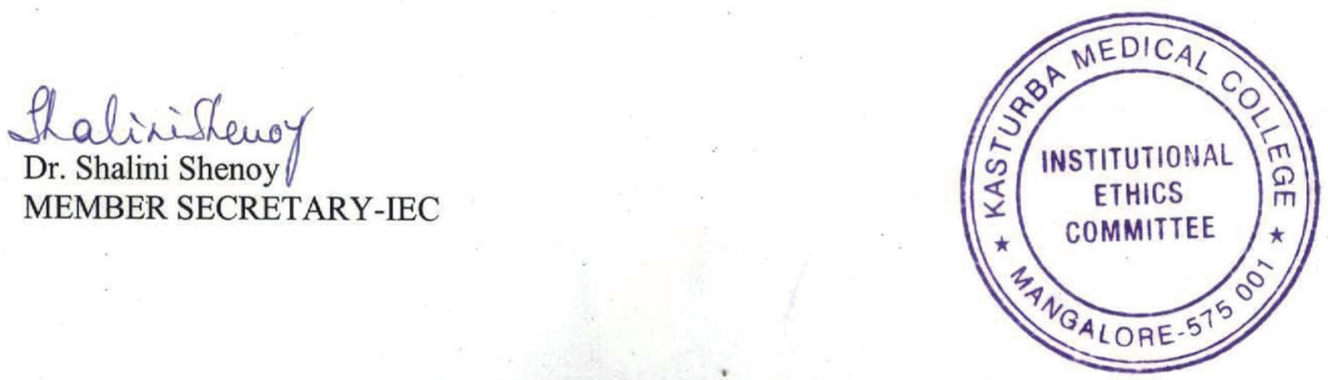

Post Box No. 53. Light House Hill Road, Hampankatta, Mangalore - 575 001, Karnataka, India Phone: 918242422271 Fax: 918242428183 E-mail: kmcmng@manipal.edu Website: www.manipal.edu/kmcmnglore Telegrams: 'KEYEMSEE' 